\title{
ESTIMATIVA DE POLUIÇÃO AMBIENTAL NO TRANSPORTE DE CARGAS POR RODOVIA E HIDROVIA
}

L. A. Brasileiro; C. A. Consoni Neto; F. A. C. Costa; G. Kitsandonis; I. de O. Zago; J. P. N. da S. Mosin; K. S. Masselani; L. A. Torres; L. B. Diederichsen; M. E. R. Rodrigues; M. S. R. da Cunha; M. S. Keller; N. S. Vaz; T. de Menezes; V. A.

Figueiredo

UNESP - Universidade Estadual Paulista

PET Engenharia Civil, UNESP, Ilha Solteira, São Paulo

Palavras - chave: Meio ambiente; Navegação; Poluição

\section{Introdução}

O transporte de cargas é um sistema de vital importância para a economia de um país, em geral, e para segmentos da população, em particular: desde o produtor, passando pelas empresas de distribuição, até o consumidor final.

O modelo do transporte de cargas no Brasil surgiu pelo modo ferroviário alimentando os portos marítimos e, assim, fortalecendo, o transporte hidroviário (RIBEIRO, 2014). A partir do processo de industrialização do Brasil, o modo ferroviário e aquaviário entraram em declínio, abrindo espaço para a indústria automobilística, que se tornou cada vez mais acessível, consolidando o modo rodoviário na matriz de transportes (SCHIMIDT, 2011). Atualmente, a movimentação de insumos e produtos ainda prioriza o modo rodoviário, como mostra a matriz do transporte de cargas no Brasil: rodovia $61,1 \%$; ferrovia $20,7 \%$; aquavia $13,6 \%$ (hidroviário e marítimo); dutovia $4,2 \%$ e aerovia $0,4 \%$ (CNT, 2018).

Entretanto, o grande volume da movimentação de cargas por modo rodoviário congestiona e causa desgaste nas rodovias, aumentando o tempo e o valor do produto final, pois eleva o custo de manutenção da infraestrutura, e diminui a qualidade do transporte (IPEA, 2016). O frete rodoviário apresenta custo elevado em relação aos modos ferroviário e hidroviário, segundo Ribeiro e Ferreira (2002), 
podendo chegar a $60 \%$ das despesas logísticas. Além disto, o transporte rodoviário gera impactos ambientais, tais como: emissão de poluentes atmosféricos, aumento do nível de ruídos, proliferação de vetores e doenças, alteração da qualidade das águas superficiais e subterrâneas e aumento de material particulado (MENEZES, 2019).

O sistema intermodal do transporte de carga aumentará a competitividade dos produtos brasileiros no mercado mundial, pois haverá redução dos custos de transportes com a utilização do modo hidroviário (FELIPE JÚNIOR e SILVEIRA, 2008). Outras vantagens na escolha do modo hidroviário são: possibilidade de movimentação internacional de cargas, grande volume de cargas com baixo custo variável e tendência a menor poluição ao meio ambiente. Atualmente, a Hidrovia Tietê-Paraná permite o escoamento de insumos e produtos do Centro-Oeste em direção ao Porto de Santos, com um frete mais reduzido porque a carga transportada apresenta baixo valor agregado e menor consumo de energia. Portanto, o objetivo deste trabalho é apresentar uma análise ambiental do transporte de cargas realizado pela rodovia paralela à Hidrovia Tietê - Paraná. A análise consiste no cálculo da emissão de Dióxido de Carbono pelo transporte atual por rodovia, verificação da possibilidade do transporte pela hidrovia e estimativa de redução da emissão.

\section{Metodologia}

O método utilizado para realizar a análise ambiental do transporte de cargas na hidrovia em estudo é denominado Top - Down, que é recomendado pelo MME (2014) para estimar as emissões de GEE (Gases de Efeito Estufa), utilizando as seguintes equações:

$\mathrm{CC}=\mathrm{CA} \times$ Fconv $\times 45,2 \times 10^{-3} \times$ Fcorr

Onde:

CC - Consumo de energia (TJ);

CA - Consumo de combustível $\left(\mathrm{m}^{3}\right)$;

Fconv - Fator de conversão da unidade física da quantidade de combustível para tEP (tonelada Equivalente de Petróleo); e

Fcorr - Fator de correção do PCS (Poder Calorífico Superior) para PCI (Poder Calorífico Inferior). 
$\mathrm{QC}=\mathrm{CC} \times$ Femiss $\times 10^{-3}$

Onde:

QC - Conteúdo de carbono $(\mathrm{GgC})$;

CC - Consumo de energia (TJ); e

Femiss - Fator de emissão de carbono (tC/TJ).

$\mathrm{ECO}_{2}=\mathrm{QC} \times 44 / 12$

Onde:

$\mathrm{ECO}_{2}$ - Emissão de $\mathrm{CO}_{2}(\mathrm{GgC})$; e

QC - Conteúdo de carbono $(\mathrm{GgC})$.

O Quadro 1 apresenta os valores dos fatores utilizados nas equações para o cálculo da emissão de Dióxido de Carbono $\left(\mathrm{CO}_{2}\right)$ e suas respectivas fontes. Os valores são iguais para os modos rodoviários e hidroviários porque ambos utilizam o mesmo combustível (óleo diesel).

Quadro 1: Fatores utilizados no cálculo da emissão de dióxido de carbono

\begin{tabular}{|l|l|l|l|}
\hline FATOR & F CONV $_{\text {C }}$ & $F_{\text {CORR }}$ & $F_{\text {EMISS }}$ \\
\hline VALOR & 0,848 & 0,95 & 20,2 \\
\hline FONTE & $($ MME, 2014) & $($ MME, 2014) & (MMA, 2011) \\
\hline
\end{tabular}

É fundamental observar que o gás analisado (Dióxido de Carbono) é um dos principais causadores da intensificação do efeito estufa, uma vez que este possui capacidade de absorção de radiação infravermelha. O Dióxido de Carbono mantém o calor nas camadas mais baixas da atmosfera, causando um desequilíbrio no clima e aumentando a temperatura, podendo resultar em desastres naturais.

\section{Resultados e discussão}

Segundo DER (2018), atualmente, há um volume de cargas pela rodovia paralela à Hidrovia Tietê - Paraná igual a 249.392.272,5 ton/ano, gerando um tráfego pesado de 7.917.215 caminhões/ano.

O transporte de cargas por essa frota de caminhões apresenta consumo médio de combustível igual a 1.840.217.540,5 m³/ano; o fator de conversão do Diesel é 0,848 $\mathrm{tEP} / \mathrm{m}^{3}$ e o fator de correção para combustível líquido é 0,95 (MME, 2014). 
Substituindo estes valores na Equação 1, determina-se que o consumo de energia para o transporte atual de cargas por rodovia é CC $=67.008 .062,1 \mathrm{TJ} / \mathrm{ano}$.

Substituindo o consumo de energia $C C=67.008 .062,1 \mathrm{TJ} / \mathrm{ano}$ e o fator de emissão do Diesel $=20,2$ tC/TJ $(M M A, 2011)$ na Equação 2, calcula-se o conteúdo de carbono $\mathrm{QC}=1.353 .562,8 \mathrm{GgC} / \mathrm{ano}$ que é gerado no transporte atual de cargas por rodovia.

E, finalmente, substituindo o conteúdo de carbono $Q C=1.353 .562,8 \mathrm{GgC} / \mathrm{ano}$ na Equação 3, determina-se que a emissão de $\mathrm{CO}_{2}$ (Dióxido de Carbono) devido ao transporte atual de cargas por rodovia é 4.963.063,6 GgC/ano.

Segundo AHRANA (2018) a Hidrovia Tietê - Paraná, mostrada na Figura 1, apresenta capacidade de 13.100 .000 ton/ano, mas transporta apenas aproximadamente 3.100 .000 ton/ano; portanto há uma capacidade ociosa de 10.000.000 ton/ano.

Figura 1: Mapa temático da Hidrovia Tietê - Paraná

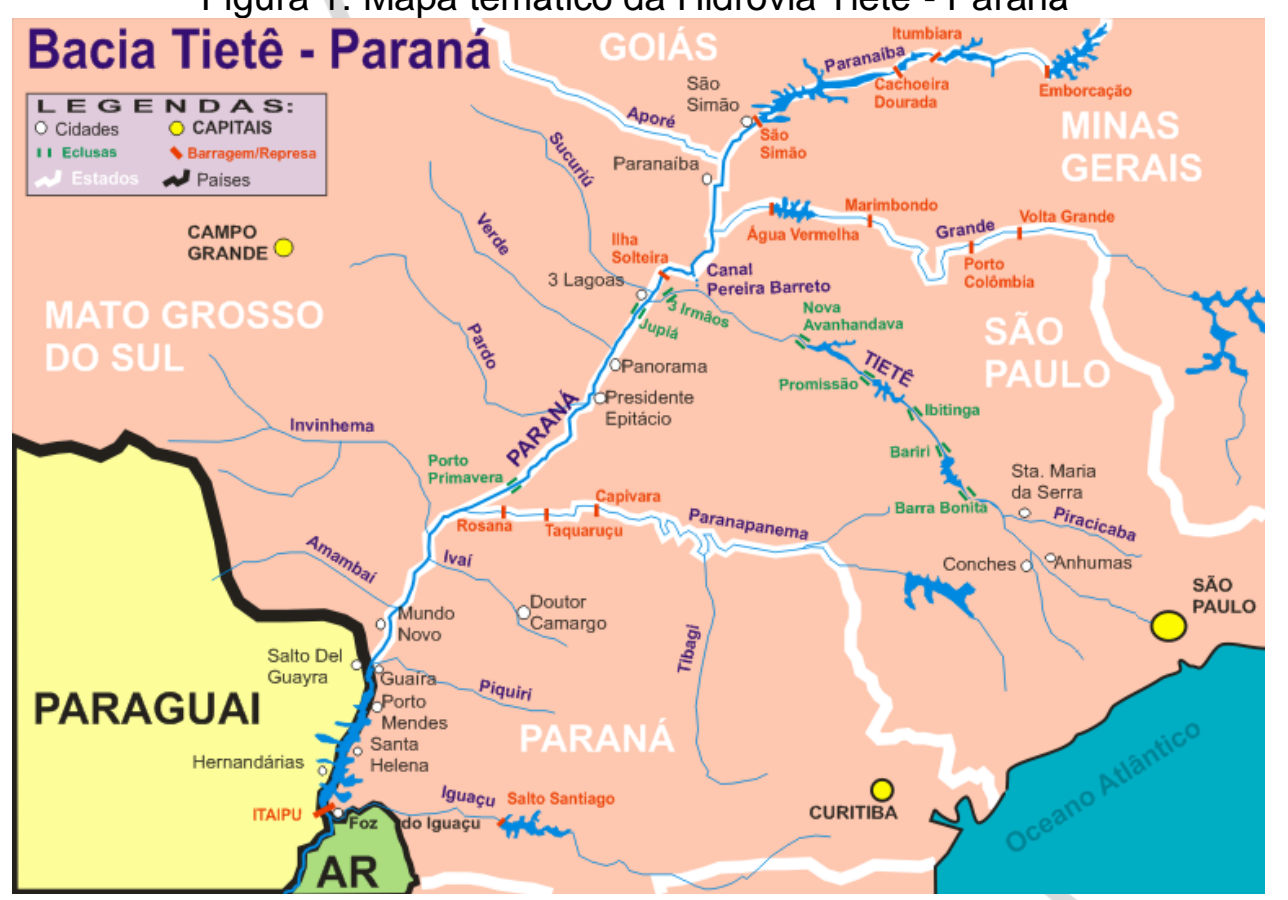

Fonte: AHRANA (2018)

Se a capacidade ociosa da hidrovia fosse utilizada transferindo parte da carga transportada por rodovia, haveria uma diminuição do tráfego pesado igual a 317.460 caminhões/ano. Aplicando o método Top - Down na operação da frota de 317.460 caminhões/ano; calcula-se uma emissão de $\mathrm{CO}_{2}$ (Dióxido de Carbono) igual a 393.384,2 GgC/ano por rodovia. 
Mas, se essa quantidade de carga equivalente à operação de 317.460 caminhões/ano fosse transportada por hidrovia, pela aplicação do método Top Down, haveria apenas uma emissão de $\mathrm{CO}_{2}$ (Dióxido de Carbono) igual a 58.220,8 GgC/ano por hidrovia.

Resumidamente, As Tabelas 1 e 2 apresentam os resultados da análise da carga total transportada por rodovia e da carga parcial que pode ser transportada por hidrovia, respectivamente.

Tabela 1: Resultados da emissão de $\mathrm{CO}_{2}$ para o transporte da carga total por rodovia

\begin{tabular}{|l|l|l|l|l|l|}
\hline \multicolumn{2}{|c|}{ RODOVIA } & CA (m $\left.{ }^{3} / \mathbf{a n o}\right)$ & CC (TJ/ano) & QC (GgC/ano) & ECO $_{2}(\mathbf{G g C / a n o})$ \\
\hline Carga total & 7.917 .215 & 1.840 .217 .540 & $67.008 .062,1$ & $1.353 .562,8$ & $4.963 .063,6$ \\
\hline
\end{tabular}

Tabela 2: Resultados da emissão de $\mathrm{CO}_{2}$ pela carga parcial por rodovia e hidrovia

\begin{tabular}{|c|c|c|c|c|c|}
\hline CARGA & PARCIAL & $\mathrm{CA}\left(\mathrm{m}^{3} / \mathrm{ano}\right)$ & CC (TJ/ano) & QC (GgC/ano) & $\mathrm{ECO}_{2}(\mathrm{GgC} / \mathrm{ano})$ \\
\hline RODOVIA & 317.460 & 145.860 .000 & $5.311 .217,7$ & $107.286,6$ & $393.384,2$ \\
\hline HIDROVIA & 317.460 & 21.587 .280 & $786.060,2$ & $15.878,4$ & $58.220,8$ \\
\hline
\end{tabular}

\section{Conclusões}

Os resultados alcançados demonstram que se utilizar a hidrovia em sua capacidade há uma diminuição na emissão de $\mathrm{CO}_{2}$ (Dióxido de Carbono) aproximadamente igual a $8 \%$ gerada atualmente pelo tráfego rodoviário de cargas nos trechos analisados. $O$ transporte da carga transferida para a hidrovia gera uma emissão de $\mathrm{CO}_{2}$ (Dióxido de Carbono) aproximadamente igual 1\%; pois cada caminhão contribui com 0 equivalente a 190 comboios hidroviários na emissão deste tipo de poluente. Portanto, como resultado final teria uma diminuição de aproximadamente $7 \%$ de poluentes no meio ambiente devido à utilização da hidrovia para o transporte de apenas $4 \%$ do volume de cargas atualmente transportado pela rodovia.

Ao analisar a emissão do Dióxido de Carbono, é fato que o transporte hidroviário, comparativamente ao modo rodoviário, gera menor impacto ambiental e se apresenta como uma boa alternativa ecológica para o transporte de cargas. 


\section{Referências}

AHRANA - Administração da Hidrovia Tietê Paraná. Cadernos de Navegação. Departamento Nacional Infraestrutura Transportes, Volumes I-IV. São Paulo, 2018.

CNT - Confederação Nacional do Transporte. Boletim Estatístico № 08. Revista Transporte Atual. Ano XXIV, № 276, SEST - Serviço Social do Transporte / SENAT - Serviço Nacional de Aprendizagem do Transporte, 84 p. Brasília, 2018.

DER - Departamento de Estradas de Rodagem. Volume Médio Diário das Rodovias VDM. www.der.sp.gov.br, 2018.

FELIPE JÚNIOR, N. F. e SILVEIRA, M. R. A Hidrovia Tietê-Paraná e as Redes Intermodais. Revista Formação, № 15, Volume 1, pp. 97-107, 2008.

IPEA - Instituto de Pesquisa Econômica Aplicada. Logística e Transportes no Brasil. Relatório Técnico, 30 p. Rio de Janeiro, 2016.

MENEZES, V. S. Impactos Ambientais do Transporte Rodoviário. UFF Universidade Federal Fluminense, 13 p. Rio de Janeiro, 2019.

MME - Ministério de Minas e Energia. Balanço Energético Nacional. EPE - Empresa de Pesquisa Energética, 282 p. Rio de Janeiro, 2014.

RIBEIRO, L. O. M. A Intermodalidade e o Transporte de Carga no Brasil. In: Simpósio de Administração da Produção, Logística e Operações Internacionais, FGV - Fundação Getúlio Vargas, pp. 1-14. São Paulo, 2014.

RIBEIRO, P. C. C. e FERREIRA, K. A. Logística e Transportes: Uma discussão sobre os Modais de Transporte e o Panorama Brasileiro. In: Encontro Nacional de Engenharia de Produção, ABEPRO, 2002, p. 8. Curitiba, 2002.

SCHMIDT, E. L. O Sistema de Transporte de Cargas no Brasil e sua Influência sobre a Economia. Monografia - Departamento de Ciências Econômicas, Universidade Federal de Santa Catarina, 88p. Florianópolis. 2011. 